\title{
Destruction of Escherichia coli and Enterococcus faecalis Using Low Frequency Ultrasound Technology: A Response Surface Methodology
}

\author{
Mitra Gholami ${ }^{1,2,}$; Roya Mirzaei ${ }^{1}$; Rashin Mohammadi ${ }^{3}$; Zohre Zarghampour ${ }^{4}$; Akhtar \\ Afshari $^{1}$ \\ ${ }^{1}$ Department of Environmental Health Engineering, School of Public Health, Iran University of Medical Sciences, Tehran, IR Iran \\ 2 Occupational Health Research Center, Iran University of Medical Sciences, Tehran, IR Iran \\ ${ }^{3}$ Department of Cellular-Molecular Biology, College of Science, University of Tehran, Tehran, IR Iran \\ ${ }^{4}$ Tehran Water and Wastewater Company, Tehran, IR Iran \\ ${ }^{*}$ Corresponding author: Mitra Gholami, Department of Environmental Health Engineering, School of Public Health, Iran University of Medical Sciences, Tehran, IR Iran. Tel: +98- \\ 2188777674, Fax:+98-2188779487, E-mail: gholamim@tums.ac.ir; gholamimitra@ymail.com
}

Received: August 14, 2013; Revised: October 19, 2013; Accepted: October 20, 2013

\begin{abstract}
Background: Ultrasonic irradiation has been used for a variety of purposes. Ultrasound is able to inactivate bacteria and deagglomerate bacterial clusters through a number of physical, mechanical and chemical effects.

Objectives: The current study aimed to investigate the effect of ultrasound technology on Escherichia coli (E. coli) (ATCC 25922) and Enterococcus faecalis (E. faecalis) (ATCC 11700) reduction in drinking water.

Materials and Methods: Fifty $\mathrm{mL}$ inoculated samples of drinking water were sonicated by ultrasonic homogenizer with the dissipated power (Pdiss) of 70 watt and $20 \mathrm{KHz}$ frequency at 2, 6 and 10 pulse/s ultrasound cycles, with the retention time of 5 and 10 minutes and also the microbial suspension concentration of 3, 6 and $9 \mathrm{CFU} / \mathrm{mL}$. Microbial colonies were counted by McFarland and plate count methods. Response surface methodology (RSM) was applied to optimize the operating conditions. Design-Experts 8 (trial version) was employed in order to perform an ANOVA to analyze the ultrasound efficiency for the selected bacterial inactivation.

Results: The results showed that E. coli and E. faecalis were effectively treated at 10 pulse/s in 9 minutes and 6 log CFU/mL bacterial suspension ( $\mathrm{P}<0.0001$ for E. coli with $99.99 \%(4 \log )$ and $\mathrm{P}=0.0002$ for E. faecalis with $97.5 \%$ removal efficiency). High coefficient of correlation ( $\mathrm{R}^{2}=99.85$ for E. coli and $\mathrm{R}^{2}=99.49$ for $E$. faecalis) indicated that the model was reproducible.

Conclusions: ANOVA results showed that the effect of cycle and time on the selected bacterial removal efficiency were more important than that of the microbial concentration.
\end{abstract}

Keywords: Escherichia coli; Enterococcus faecalis; Sonication; Disinfection

\section{Background}

Ultrasonic irradiation has been used for a variety of purposes (1). Inactivation of microorganisms is an essential step in water treatment as the final safeguard against water-borne microbial disease (2). There are the most widely physical and chemical technologies used for water disinfection (3). Chemical germicides are usually effective and relatively cheap, but can lead to the formation of hazardous organic by-products (especially in chlorination) (4). These methods are not environmentally friendly. Chemical methods are also limited by severe mass transfer limitations resulting in decreased disinfection rates (5). The potency of certain physical techniques, such as ultraviolet irradiation is limited in highly light scattering or absorbing solutions (6). On the other hand, some species of bacteria produce colonies and spores that agglomerate in spherical clusters. Application of biocide can destroy microorganisms on the surface of such clusters, but often leaves most of the inner bacteria intact. Flocs of fine particles can entrap bacteria and protect them against disinfection (7). Therefore, it is necessary to develop an advanced and eco- friendly method for inactivation of microorganisms in aquatic environments. Sonication is an eco-friendly alternative for water purification. The sound waves generated by this treatment can be utilized to eliminate microorganisms and organic pollutants in water.

Since human ear cannot detect the ultrasound waves because of their high frequency, they sound silent. Ultrasound Technology can be applied in gas, liquid and solid phase. The use of this process in liquid phase is 
called cavitations (8). In ultrasound waves, the vibration of the molecules in the environment, where the wave is being spread, transmits the energy (9). These waves produce strong cavitations in aqueous solution causing shock wave and reactive free radicals $\left(\mathrm{OH}, \bullet \mathrm{HO}_{2}, \bullet \mathrm{O}\right)$ by the violate collapse of the cavitations bubble (3). These effects contribute to the physical inactivation of microbial structures and also the degradation of toxic elements (10, 11). Ultrasonic irradiation has been used for a variety of purposes (1). Ultrasound is able to inactivate bacteria and de-agglomerate bacterial clusters through a number of physical, mechanical and chemical effects (10). The lethal and biological effects of ultrasound were first reported in 1930 s (12). In the 1960s researches concentrated on understanding the ultrasound mechanism in microbial inactivation (13). By 1975, it was shown that brief exposure to ultrasound caused thinning of cell walls, and attributed to the release of the cytoplasm membrane from the cell wall (14).

Ultrasonic process efficiency for elimination or inactivation of bacteria,fungi, viruses and nematodes has been conducted in a number of studies which include E. coli (11, 12, 14-17), Pseudomonas aeroginosa and Staphylococcus (18), fungi $(19,20)$ and viruses $(21)$. When ultrasound irradiation is coupled with ultraviolet light, it is able to achieve $97 \%-100 \%$ removal of biological growth. Ultrasound at lower frequencies (20 - $100 \mathrm{kHz}$ ), classified as "power ultrasound", and originally committed to water treatment, was applied to waste activated sludge disinfection for improving anaerobic stabilization. Low frequency has an important effect on the bacterial mortality $(22,23)$.

\section{Objectives}

This paper addresses the disinfection of drinking water using low frequency sonication in order to determine the fundamental effects of changes in cycle (power) and sonication time on E. coli and E. faecalis elimination. This study was innovative regarding the comparison of ultrasound efficiency on destruction of gram positive and gram negative water indicator bacteria, application of response surface methodology as a statistical method, and application of McFarland method with dilution and plate count.

\section{Materials and Methods}

\subsection{Microorganisms and Inoculums Preparation}

Experiments were conducted on laboratory scale using E. coli (ATCC 25922) purchased from Pasteur Institute of Iran and E. faecalis (ATCC 11700) bought from Department of Microbiology, the Iranian Research Organization for Science and Technology. For reviving Freeze-dried cultures of the selected bacteria, after striking the vials, 0.5 $\mathrm{mL}$ of azide dextrose broth was added to the freeze -dried cells with a sterile Pasteur pipette, and mixed properly. Then the total mixture was transferred to a vessel containing $500 \mathrm{~mL}$ of azide dextrose broth and incubated at $37{ }^{\circ} \mathrm{C}$ for 18 - 24 hours. Following incubation, $0.1-1 \mathrm{~mL}$ of incubated mixture was serially diluted with buffered peptone water (BPW) to obtain different dilutions and cell concentrations. These sets of assorted dilutions were used to identify the concentration of viable micro-organism in a fixed amount of a liquid by McFarland turbidity standards method (24). This method estimates the approximate amount of bacteria in suspension.

\subsection{Sonication}

Sonoplus ultrasonic homogenizer (CM2070) was applied with operating fixed frequency of $20 \mathrm{kHz}$ and variable electric power output up to $70 \mathrm{w}$. The ultrasound treatment experiments were carried out separately under the same conditions for both selected bacteria.

\subsection{Experimental Setup}

Fifty $\mathrm{mL}$ drinking water samples were sonicated at 20 $\mathrm{kHz}$ and 70w (dissipated power " $\mathrm{P}_{\text {diss }}$ ") at different time lengths, cycles and selected bacterial concentrations (Table 1).

\begin{tabular}{llll}
\hline \multicolumn{4}{l}{ Table 1. Level of Variables } \\
\hline $\begin{array}{l}\text { Level of } \\
\text { Variables }\end{array}$ & $\begin{array}{l}\text { Cycle, } \\
\text { pulse/s }\end{array}$ & $\begin{array}{l}\text { Concentration, } \\
\text { CFU/mL }\end{array}$ & Time, min \\
\hline $\mathbf{1}$ & 2 & 3 & 5 \\
$\mathbf{2}$ & 6 & 6 & 7 \\
$\mathbf{3}$ & 10 & 9 & 9 \\
\hline
\end{tabular}

\subsection{Statistical Analysis}

To optimize runs and data analysis, Box-Benken statistical design, based on response surface methodology (RSM), was applied to investigate effects of the selected variables and minimize the number of experimental runs $(25,26)$. RSM is a developing and optimizing process in which the response of interest is influenced by several factors (27). Therefore, the effect of three explanatory factors (sonoplus ultrasonic homogenizer cycle, time and log of bacteria) on reduction of the selected bacteria was carried out using different types of cell suspension into seventeen experimental runs. An analysis of variance (ANOVA) was performed by Design-Experts 8 - Trial version. Also, the effect of ultrasound and regression coefficients of individual linear, quadratic and interaction term were measured for the bacteria.

\subsection{Preparation of Bacteria for Test}

For thawing E. coli (ATCC 25922), aseptically, $0.5 \mathrm{~mL}$ of TSB was added to the freeze-dried material, by pasture pi- 
pette, and mixed well. For E. faecalis (ATCC 11700), $0.5 \mathrm{~mL}$ of azide dextrose broth was used. The suspensions were transferred to an EMB agar slant for E-coli, and to a Pfizer selective Enterococcus Agar for E. faecalis. Finally, these cultures were incubated at $35^{\circ} \mathrm{C}-37^{\circ} \mathrm{C}$ for 18 - 24 hours.

\section{Results}

\subsection{Ultra Sound-Based Reduction of Escherichia} coli (ATCC 25922) and Entrococcus Fecalis (ATCC 11700) Population in Suspension

The current investigation studied the effect of three main variables (time, cycle, and microbial concentration) to optimize ultrasound performance on inactivation of two indicator bacteria, E. coli and E. faecalis. The rejection values (response) at various experiments and conditions are shown in Table 2.

As it can be seen in Table 2, the maximum reduction for E. coli was $99.99 \%(4 \log$ ) with $\mathrm{P}<0.0001$ and for $E$. faecalis was $97.5 \%$ with $\mathrm{P}=0.0002$ at 10 pulse/s in 9 minutes and $6 \log \mathrm{CFU} / \mathrm{mL}$ bacterial suspension. Application of US technology for disinfection process was described in some articles $(28,29)$. The lethal effect of ultrasonication was also reported for reduction of Yersinia enterocolitica, Bacillus subtilis spores, Listeria monocytogenes, Salmonella spp, Aeromonas hydrophila, Legionella pneumophila, Acanthamoeba castellanii, Saccharomyces cerevisiae, Pseudomonas aeroginosa and Staphylococcus aurous
$(4,18,25,30,31)$.

\subsection{Response Surface Modeling for Escherichia coli and Enterococcus faecalis}

Response surface Methodology (RSM) is an important branch of experimental design and a critical technology in developing new processes and optimizing their performance. The objective of quality improvement, including reduction of variability, improved process and product performance, can be often accomplished directly using RSM. Regression analyses of the experimental data with ANOVA, and results of the quadratic models for E. coli and E. faecalis, were summarized in Table 3 and 4.

A, B and C are coded variables for sonication time, sono-reactor cycle and initial cell concentration, respectively. The normal probability plots of the studentized residuals for the selected bacteria are shown in Figure 1. According to Figure 1, the data for both bacteria were normally distributed. In these graphs, residual value indicates the difference between the obtained response and the fitted value under the theorized model. Therefore, the model was adequate for prediction within the range of experimental data.

\subsection{Predicted Second Order Polynomial Equations}

The predicted second order polynomial equations, after neglecting statistically non-significant values for the selected bacteria, are given in Table 5 .

\begin{tabular}{|c|c|c|c|c|c|c|c|c|}
\hline Number & $\begin{array}{l}\text { E. coli, } \\
\text { SD }\end{array}$ & $\begin{array}{l}\text { E.faecalis, } \\
\text { SD }\end{array}$ & Run & $\begin{array}{l}\text { Factor A Contact } \\
\text { Time, min }\end{array}$ & $\begin{array}{l}\text { Factor B } \\
\text { Cycle, pulse/s }\end{array}$ & $\begin{array}{l}\text { Factor C Log, } \\
\text { CFU/mL }\end{array}$ & $\begin{array}{l}\text { E. coli } \\
\text { inactivtion, \% }\end{array}$ & $\begin{array}{l}\text { E.faecalis } \\
\text { inactivtion, \% }\end{array}$ \\
\hline 1 & 8 & 12 & 1 & 9.00 & 6.00 & 9.00 & 91 & 92 \\
\hline 2 & 16 & 3 & 2 & 7.00 & 6.00 & 6.00 & 49 & 64.2 \\
\hline 3 & 10 & 10 & 3 & 7.00 & 10.00 & 3.00 & 67 & 60 \\
\hline 4 & 9 & 2 & 4 & 7.00 & 2.00 & 3.00 & 41 & 43 \\
\hline 5 & 17 & 9 & 5 & 7.00 & 6.00 & 6.00 & 47 & 63.1 \\
\hline 6 & 14 & 16 & 6 & 7.00 & 6.00 & 6.00 & 50 & 65 \\
\hline 7 & 3 & 8 & 7 & 5.00 & 10.00 & 6.00 & 32 & 42 \\
\hline 8 & 1 & 17 & 8 & 5.00 & 2.00 & 6.00 & 10 & 32 \\
\hline 9 & 7 & 11 & 9 & 5.00 & 6.00 & 9.00 & 27 & 34 \\
\hline 10 & 12 & 15 & 10 & 7.00 & 10.00 & 9.00 & 71 & 75 \\
\hline 11 & 5 & 14 & 11 & 5.00 & 6.00 & 3.00 & 16 & 30 \\
\hline 12 & 11 & 7 & 12 & 7.00 & 2.00 & 9.00 & 50 & 44 \\
\hline 13 & 13 & 6 & 13 & 7.00 & 6.00 & 6.00 & 52 & 58 \\
\hline 14 & 15 & 1 & 14 & 7.00 & 6.00 & 6.00 & 51 & 62 \\
\hline 1516 & 6 & 5 & 15 & 9.00 & 6.00 & 3.00 & 93 & 87 \\
\hline 17 & 2 & 4 & 16 & 9.00 & 2.00 & 6.00 & 81 & 82 \\
\hline 18 & 4 & 13 & 17 & 9.00 & 10.00 & 6.00 & 99.99 & 97.5 \\
\hline
\end{tabular}


Gholami M et al.

\begin{tabular}{|c|c|c|c|c|c|c|}
\hline Source & Sum of Squares & df & Mean Square & F value & P value, Probability $>$ F value & Significance Level \\
\hline Model & 11050.40951 & 11 & 1004.582682 & 298.9829412 & $<0.0001$ & Significant \\
\hline Time (A) & 9799.300013 & 1 & 9799.300013 & 2916.458337 & $<0.0001$ & \\
\hline Cycle (B) & 967.7800125 & 1 & 967.7800125 & 288.0297656 & $<0.0001$ & \\
\hline $\log$, CFU/mL (C) & 135.7050066 & 2 & 67.85250329 & 20.19419741 & 0.0040 & \\
\hline $\mathbf{A B}$ & 2.265025 & 1 & 2.265025 & 0.674114583 & 0.449 & \\
\hline AC & 42.7550125 & 2 & 21.37750625 & 6.362353051 & 0.0423 & \\
\hline BC & 10.7650125 & 2 & 5.38250625 & 1.601936384 & 0.2900 & \\
\hline A2 & 31.23711184 & 1 & 31.23711184 & 9.296759477 & 0.0285 & \\
\hline B2 & 43.75816447 & 1 & 43.75816447 & 13.02326324 & 0.0154 & \\
\hline Residual & 16.8 & 5 & 3.36 & & & \\
\hline Lack of fit & 2 & 1 & 2 & 0.540540541 & 0.5030 & not significant \\
\hline Pure error & 14.8 & 4 & 3.7 & & & \\
\hline Cor total & 11067.20951 & 16 & & & & \\
\hline
\end{tabular}

\begin{tabular}{|c|c|c|c|c|c|c|}
\hline Source & Sum of Squares & df & Mean Square & F value & $\begin{array}{l}\text { P value Probability }> \\
\text { F value }\end{array}$ & $\begin{array}{l}\text { Significance } \\
\text { Level }\end{array}$ \\
\hline Model & 7114.521824 & 11 & 646.7747112 & 89.53881984 & $<0.0001$ & Significant \\
\hline Time (A) & 6077.53125 & 1 & 6077.53125 & 841.3671194 & $<0.0001$ & \\
\hline Cycle (B) & 675.28125 & 1 & 675.28125 & 93.48523548 & 0.0002 & \\
\hline $\log , \mathrm{CFU} / \mathrm{mL}(\mathrm{C})$ & 174.8326053 & 2 & 87.41630263 & 12.10182222 & 0.0121 & \\
\hline $\mathbf{A B}$ & 7.5625 & 1 & 7.5625 & 1.046944652 & 0.3531 & \\
\hline AC & 11.53125 & 2 & 5.765625 & 0.798187142 & 0.5002 & \\
\hline BC & 112.28125 & 2 & 56.140625 & 7.772049866 & 0.0292 & \\
\hline A2 & 40.00760526 & 1 & 40.00760526 & 5.538611355 & 0.0653 & \\
\hline B2 & 19.78128947 & 1 & 19.78128947 & 2.738501187 & 0.1589 & \\
\hline Residual & 36.117 & 5 & 7.2234 & & & \\
\hline Lack of fit & 6.125 & 1 & 6.125 & 0.816884503 & 0.4172 & not significant \\
\hline Pure error & 29.992 & 4 & 7.498 & & & \\
\hline Cor total & 7150.638824 & 16 & & & & \\
\hline
\end{tabular}

A

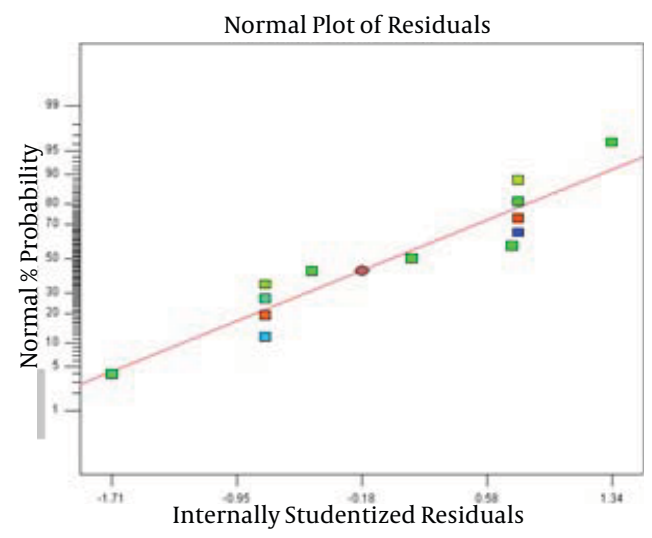

B

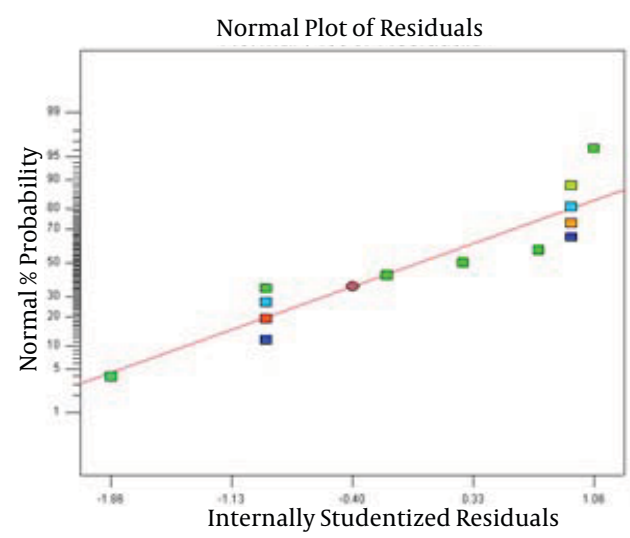

Figure 1. Normal Probability Plot of the Studentized Residuals for Escherichia coli (I) and Enterococcus faecalis (II) 
Gholami M et al.

Table 5. Predicted Second Order Polynomial Equations for the Selected Bacteria ${ }^{a}$

\begin{tabular}{llll}
\hline Response & Equations & P value & $\mathbf{R}^{2}$ \\
\hline Escherichia coli $\left(\mathrm{Y}_{1}\right)$ & $\mathrm{Y}_{1}(\%)=50.38+8.57^{*} \mathrm{~A}+1.05^{*} \mathrm{~B}+16.00^{*} \mathrm{C}[1]+0.071^{*} \mathrm{C}[2]-0.094^{*} \mathrm{AB}-1.62^{*} \mathrm{AC}+0.084^{*}$ & $<0.0001$ & 99.85 \\
& $\mathrm{AC}-0.31^{*} \mathrm{BC}+0.13^{*} \mathrm{BC}+0.68^{*} \mathrm{~A}^{2}+0.20^{*} \mathrm{~B}^{2}$ & $<0.0001$ & 99.49 \\
Enterococcus faecalis $\left(\mathrm{Y}_{2}\right)$ & $\mathrm{Y}_{2}(\%)=59.27+27.96^{*} \mathrm{~A}+10.13{ }^{*} \mathrm{~B}+3.13^{*} \mathrm{C}[1]-1.60^{*} \mathrm{C}[2]+1.37^{*} \mathrm{AB}+0.25 *$ & \\
& $\mathrm{AC}[1]+0.79 * \mathrm{AC}[2]+3.50^{*} \mathrm{BC}[1]+1.88^{*} \mathrm{BC}[2]+3.08^{*} \mathrm{~A}^{2}-2.1{ }^{*} \mathrm{~B}^{2}$ & & \\
\hline
\end{tabular}

${ }^{\mathrm{a}} \mathrm{Y}_{1}$ and $\mathrm{Y}_{2}$ are Escherichia coli and Enterococcus faecalis population reduction (\%), respectively.

Sonication time (A) exhibited the significant interaction with $E$. coli initial concentration $(\mathrm{P}<0.0423)$ to affect reduction of $E$. coli population by ultrasound radiation, while no statistically significant changes were found among the interactions between cycle with E. coli concentration $(\mathrm{P}<0.290)$ and with time $(\mathrm{P}<0.449)$. The second order effect of time $\left(\mathrm{A}^{2}\right)$ and $E$. coli concentration $\left(B^{2}\right)$, were also significant $(P<0.0285$ and $P<0.0154)$, respectively. However, the effect of $\mathrm{A}^{2}$ was significantly ( $\mathrm{P}=$ $0.0285 \& \mathrm{~F}=9.30)$ lower than that of $\mathrm{B} 2(\mathrm{P}=0.0154$ and $\mathrm{F}$ $=13.02)$ in E. coli inactivation, based on statistical indices and visual observations (Table 3). According to the obtained results, sonication cycle and E. faecalis concentration had significant interaction in the rate of $\mathrm{E}$. faecalis inactivation (0.0292) (Table 4). It is clearly observed that E. coli and E. faecalis reduction increased with increasing the contact time (A) and cycle (B). In contrast, selected bacterial initial cell concentrations had negative effect on population reduction. According to Figure 2, sonication time was significant $(\mathrm{P}<0.0001)$ for E. coli and E. faecalis removal efficiency.

In addition, the effect of sonicating on E. coli and E. faecalis suspension at 3 level cycles (pulse/s) is demonstrated in Figure 3.

Three different initial cell numbers (3, 6, $9 \log$ CFU/mL) were used in our experiments. The effect of bacterial log on reduction rate of $E$. coli and E. faecalis was demonstrated in Figure 4.
A

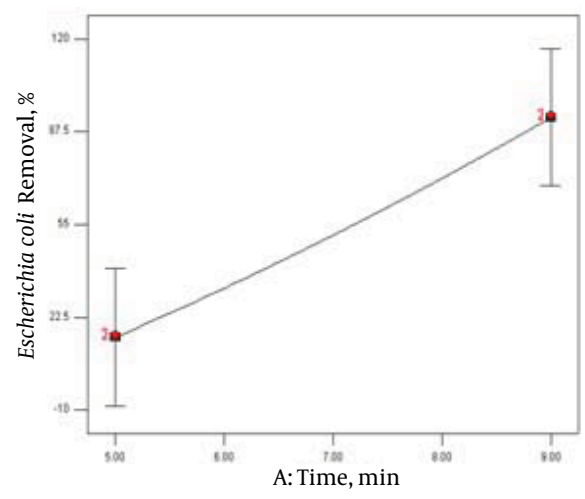

B

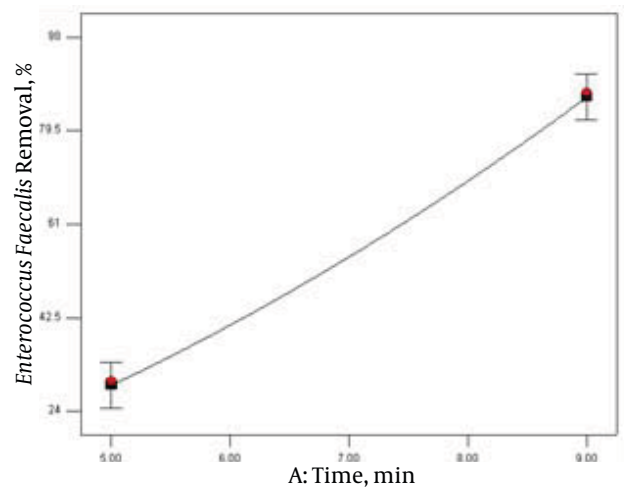

Figure 2. The Effect of Time (minute) on Removal Efficiency of Escherichia coli (I) and Enterococcus faecalis (II)

A

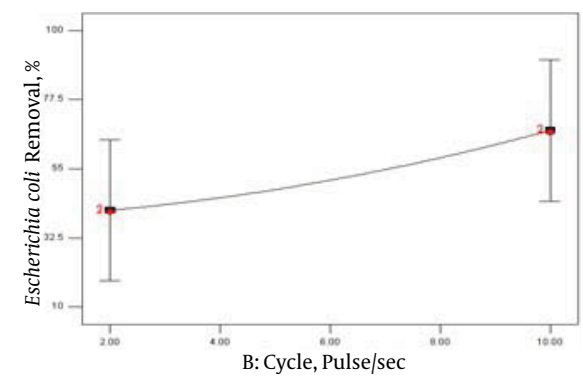

B

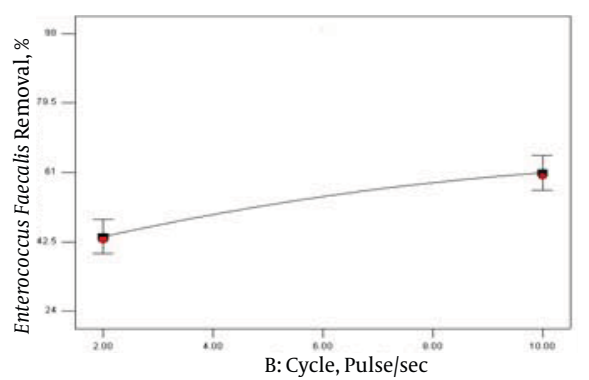

Figure 3. The Effect of Pulsation (pulse/s) on Removal Efficiency of Escherichia coli (I) and Enterococcus faecalis (II) 
A

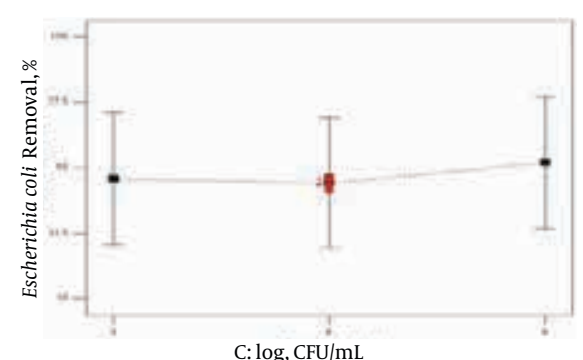

B

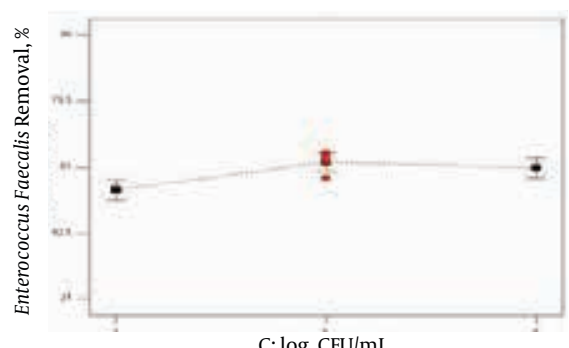

Figure 4. The Effect of Bacteria Concentration for Escherichia coli (I) and Enterococcus faecalis (II)

\section{Discussion}

\subsection{Ultra Sound-Based Reduction of Escherichia coli (ATCC 25922) and Enterococcus faecalis (ATCC 11700) Population in Suspension}

The maximum degradation of bacteria in polluted waters using ULS for pretreatment has been reported in the study by Ince et al. (32). The US process for bacterial removal is based on acoustic cavitations. These mechanisms include chemical attack by hydroxyl radicals produced by the USA, cell death because of high pressure and temperature caused by bubble collapse, and shared forces that destroyed bacterial cell membrane (33). The free radical is particularly important in biodegradation and microbial inactivation $(30,34,35)$. Exposing high mechanical pressure waves to liquids creates an acoustical stream and subsequent acoustic cavitations that cause formation, growth and implosive collapse of micro and nano-bubbles in a liquid. These bubbles have a large surface area which increases the diffusion of gas and generates intense localized heating (approximately $\left.5000^{\circ} \mathrm{C}\right)$ and high pressure (1000 ATM) $(17,22,36,37)$.

Ultrasonic cavitation affects inner membrane (the cytoplasmic membrane) of bacteria and lipoprotein bilayer is disrupted, torn and shredded. Ultrasound does not create an immediate cellular membrane rupture. In contrast, oxidizing biocide mechanism causes immediate cellular ATP release. ATP measurement indicated that due to perforation of cell wall, the ratio of extra/ intra cellular ATP increases under sonolysis (38). Thickness of cell membrane has mainly affected microbial removal efficiency (39) that is why ultrasound irradiation affects E. coli (99.99\%) more than E. faecalis (97.5\%). E. faecalis is a gram positive bacteria and its cell wall is thicker than that of E. coli. A few solutions have shown that gram-negative bacteria such as E. coli are more susceptible to this treatment than gram-positive bacteria. Even, E. coli indicated higher sensitivity than the total coliforms (40). The results of ANOVA in Tables 3 and 4, high coefficient of correlation $\left(\mathrm{R}^{2}=99.85\right.$ for $E$. coli and $\mathrm{R}^{2}=99.49$ for $E$. faecalis) along with non-significant lack of fit $(\mathrm{P}>0.05$ indicated that the model was reproducible. The coefficient of variation (CV\%), 3.36 for $E$. coli and 4.43 for E. faecalis, which were less than $5 \%$, also supported and confirmed the importance and validity of the model. It means that this model is in support of our hypothesis i.e. the relationship between sonication method and bacterial inactivation. The significance and adequacy of the model are also demonstrated by $\mathrm{F}$ value (Fisher Variation ratio), probability value (P value) and adequate precision. The ANOVA results also proved the validity of quadratic model with probability $>F$ value of less than 0.0001 for E. coli and 0.0001 for E. faecalis.

\subsection{Effect of Treatment Time}

According to ANOVA tables (Table 3 and 4) and Figure 2, the $\mathrm{P}$ value of linear coefficient of time (A) for sonication time were significant $(\mathrm{P}<0.0001)$ in both of the equations for E. coli and E. faecalis. During the ultrasound treatment, $4 \log$ reductions of $E$. coli and E. faecalis cells were achieved at 9 minutes. Lee et al. achieved up to $4 \log$ reductions in 4 min sonication (30). In Munoz et al. report, 5 minutes contact time is required to achieve a one log reduction of $E$. coli at $55^{\circ} \mathrm{C}$ in orange juice by thermosonication and high intensity light pulses (41). Similar observations in bacterial inactivation have been reported to increase residence time from 80 to 120 and 160 seconds (7). As the time of sonolysis increases, the temperature in the volume of solution rises and accelerates the diffusion processes of ions in the cell membranes (35). As a results, during US irradiation, the decomposition of pollutants in solution occurs under the effect of the oxidizing process by produced $\mathrm{OH}^{*}$ radicals due to thermal destruction, and US dynamic mixing and sharing pressure $(23,35)$. Dehgani et al. found that the fungi population decreased with Increasing sonication time (20). The influence of ULS dose on E. coli inactivation was studied at two different sonolysis time lengths (15 and 30 minutes). The results showed a synergistic effect of US on $E$. coli reduction at 15 minutes and higher US dose (15). 
Gholami M et al.

\subsection{Effect of Sonolysis Intensity}

The effect of sonicating on E. coli and E. faecalis suspension at 3 level cycles (pulse/s) is demonstrated in Figure 3. As expected, there was approximately linear increase in the inactivation of the selected bacteria, as the sonication cycle increased from 2 to10 pulse/s (Figure 3). However, comparing the slope of curves in Figure 2 and 3 demonstrated that the effect of time was significantly more than that of cycle (pulse/sec) on bacterial reduction. During pulse intervals, the active surface of bacteria had more time to adsorb ULS cavitations bubbles leading to more inactivation (42). According to the data in Marques et al. studies, in $20 \mathrm{kHz}$ frequency and intensity of $10 \mathrm{~W} / \mathrm{cm}^{2}$, they observed a large increase in the phosphatase and ATPase activity (43). Lanchun et al. (2003) results confirmed the effect of ULS irradiation on enzymatic activity of microorganisms (44). However, high intensity of ULS may be conducted to obtain $100 \%$ killing rate of microorganisms (3). Significant effect of ULS high intensity on total coliform and heterotrophic bacteria in waste water sediments has been noted in some researches (45). On the other hand, some investigations have shown the favorable effect of low intensity on plants (46). Some researchers established that low ULS power did not affect the primary physiological characteristics of microorganisms (44). The ULS intensity directly depends on ULS wave amplitude (47). The results of using ULS with different amplitude indicated that increasing the ultrasound amplitude mainly affects microbial reduction $(5,44,48,49)$.

\subsection{Effect of Specific Energy on Removal Efficiency}

The ultrasonic specific energy (Es, kJ/L) was calculated by Equation 1:

Equation 1. $E_{s}=10^{-3} X \frac{P_{\text {diss }} \mathrm{Xt}}{V}$

Where, $\mathrm{P}$ diss is dissipated ultrasound power in the samples, $\mathrm{t}$ is ultrasound irradiation time $(\mathrm{s}), \mathrm{V}$ is the volume of sample (L) (2). In the present study, P diss $=70 \mathrm{~W}$ and $\mathrm{V}=50$ $\mathrm{mL}$ and 5 - 9 time range, therefore specific energy (ES) was obtained in the range of $70-126 \mathrm{~kJ} / \mathrm{L}$. Specific energy(ES), as a reference parameter, specified the relationship between irradiation time, power and treated volume (16). It can be clearly noted that the rate of bacterial removal increases with increasing ultrasound Specific Energy (50).

\subsection{Effect of Initial Cell Number on Escherichia coli and Enterococcus faecalis Removal Efficiency}

As observed in Table 3 and 4 together with Figure 4, the effect of the selected bacterial concentration on removal efficiency was less than those of the other variables ( $\mathrm{P}=$ 0.004 for E. coli and $\mathrm{P}=0.0121$ for E. faecalis). Maximum removal efficiency for the selected bacteria was obtained in $6 \log \mathrm{CFU} / \mathrm{mL}$. Although P value $<0.05$ corroborates the statistical significance of this variable, Figure 4 demon- strated that initial concentration of E. coli has no efficient effect on bacterial reduction (51). In contrast, Tsukamoto came to a conclusion that initial log numbers of bacteria strongly influence the reduction rate, and the lowest concentration was the most effective factor on removal efficiency (19). According to Bigelow et al., sonication was able to completely remove the $E$. coli biofilms at highest exposure level (52). The results showed that a higher initial bacterial concentration needed a larger sonication time to obtain the best bacterial reduction (16). When the initial E. coli concentration increases, the $\bullet \mathrm{OH}$ radical concentration acts as the limiting factor of the disinfection processes (53). The current study demonstrated the sonolytic inactivation of E. coli, (ATCC 25922) and E. faecalis (ATCC 11700). The findings showed that, high treatment time is capable of eliminating the E. coli and $E$. faecalis in the solution, almost completely. However the effect of ultrasound irradiation on E. coli because of high sensitivity was more than that of E. faecalis. Besides treatment time, other variables that affect bacterial disruption efficiency are ultrasound cycle and initial bacterial log. Finally, it was demonstrated that bacterial inactivation increased by sonication.

\section{Acknowledgements}

This research was conducted with funding from the vice chancellor for research of Tehran University of medical sciences (Grant Number 808). I would like to extend my thanks to the technicians of the laboratory of the Environmental Health Engineering department for their help in offering the authors the resources in running the program.

\section{Authors' Contribution}

All of the authors contributed equally in this article.

\section{Financial Disclosure}

We have no financial interests related to the material in the manuscript.

\section{Funding/Support}

This research was funded by the vice chancellor for Research of Iran University of Medical Sciences (grant number: 808).

\section{References}

1. Mason TJ. Sonochemistry and sonoprocessing: the link, the trends and (probably) the future. Ultrason Sonochem. 2003;10(45):175-9.

2. Cui X, Talley JW, Liu G, Larson SL. Effects of primary sludge particulate (PSP) entrapment on ultrasonic $(20 \mathrm{kHz})$ disinfection of Escherichia coli. Water Res. 2011;45(11):3300-8.

3. Joyce E, Phull SS, Lorimer JP, Mason TJ. The development and evaluation of ultrasound for the treatment of bacterial suspensions. A study of frequency, power and sonication time on cultured Bacillus species. Ultrason Sonochem. 2003;10(6):315-8. 
4. Declerck P, Vanysacker L, Hulsmans A, Lambert N, Liers S, Ollevier F. Evaluation of power ultrasound for disinfection of both Legionella pneumophila and its environmental host Acanthamoeba castellanii. Water Res. 2010;44(3):703-10.

5. Bermúdez-Aguirre D, Corradini MG. Inactivation kinetics of Salmonella spp. under thermal and emerging treatments: A review. Food Res Int. 2012;45(2):700-12.

6. Koda S, Miyamoto M, Toma M, Matsuoka T, Maebayashi M. Inactivation of Escherichia coli and Streptococcus mutans by ultrasound at 500kHz. Ultrason Sonochem. 2009;16(5):655-9.

7. Noci F, Walkling-Ribeiro M, Cronin DA, Morgan DJ, Lyng JG. Effect of thermosonication, pulsed electric field and their combination on inactivation of Listeria innocua in milk. Int Dairy J 2009;19(1):30-35.

8. Al Bsoul A, Magnin JP, Commenges-Bernole N, Gondrexon N, Willison J, Petrier C. Effectiveness of ultrasound for the destruction of Mycobacterium sp. strain (6PY1). Ultrason Sonochem. 2010;17(1):106-10.

9. Doosti MR, Kargar R, Sayadi MH. Water treatment using ultrasonic assistance: a review. P Int Acad Ecol Envi Sci. 2012;2(2):96-110.

10. Antoniadis A, Poulios I, Nikolakaki E, Mantzavinos D. Sonochemical disinfection of municipal wastewater. J Hazard Mater 2007;146(3):492-5.

11. Furuta M, Yamaguchi M, Tsukamoto T, Yim B, Stavarache CE, Hasiba K, et al. Inactivation of Escherichia coli by ultrasonic irradiation. Ultrason Sonochem. 2004;11(2):57-60.

12. Ugarte-Romero E, Feng H, Martin SE, Cadwallader KR, Robinson SJ. Inactivation of Escherichia coli with power ultrasound in apple cider. J Food Sci. 2006;71(2):E102-E8.

13. Hughes DE, Nyborg WL. Cell disruption by ultrasound. Science 1962;138(3537):108-14.

14. Allison DG, D'Emanuele A, Eginton P, Williams AR. The effect of ultrasound on Escherichia coli viability. I Basic Microbiol. 1996;36(1):3-11

15. Naddeo V, Landi M, Belgiorno V, Napoli RM. Wastewater disinfection by combination of ultrasound and ultraviolet irradiation. $J$ Hazard Mater. 2009;168(2-3):925-9.

16. Hulsmans A, Joris K, Lambert N, Rediers H, Declerck P, Delaedt Y, et al. Evaluation of process parameters of ultrasonic treatment of bacterial suspensions in a pilot scale water disinfection system. Ultrason Sonochem. 2010;17(6):1004-9.

17. Dehghani MH. Effectiveness of Ultrasound on the Destruction of $<\mathrm{i}>$ E. coli $<\mid \mathrm{i}>$. Am JEnv Sci. 2005;1(3):187.

18. Kalantar EMA, Khosravi M, Mahmodi S. Evaluation of ultrasoundwaves effect on antibiotic resistance pseudomonas aeruginosa and staphylococcus aureus isolated from hospital and their comparison with standard species. Iran J Health Env. 2010;3(3).

19. Tsukamoto I, Yim B, Stavarache CE, Furuta M, Hashiba K, Maeda Y. Inactivation of Saccharomyces cerevisiae by ultrasonic irradiation. Ultrason Sonochem. 2004;11(2):61-5.

20. Dehghani MH, Mahvi AH, Jahed GR, Sheikhi R. Investigation and evaluation of ultrasound reactor for reduction of fungi from sewage. J Zhejiang Univ Sci B. 2007;8(7):493-7.

21. Su X, Zivanovic S, D'Souza DH. Inactivation of human enteric virus surrogates by high-intensity ultrasound. Foodborne Pathog Dis. 2010;7(9):1055-61.

22. Piyasena P, Mohareb E, McKellar RC. Inactivation of microbes using ultrasound: a review. Int J Food Microbiol. 2003;87(3):207-16.

23. Tiehm A, Nickel K, Neis U. The use of ultrasound to accelerate the anaerobic digestion of sewage sludge. Water Sci Technol. 1997;36(11):121-8.

24. McFarland J. The nephelometer: an instrument for estimating the number of bacteria in suspensions used for calculating the opsonic index and for vaccines. J Am Med Ass. 1907;49(14):11761178.

25. Kwak TY, Kim NH, Rhee MS. Response surface methodologybased optimization of decontamination conditions for Escherichia coli O157:H7 and Salmonella Typhimurium on fresh-cut celery using thermoultrasound and calcium propionate. Int $J$ Food Microbiol. 2011;150(2-3):128-35.

26. Sun Y, Li T, Yan J, Liu J. Technology optimization for polysac- charides (POP) extraction from the fruiting bodies of Pleurotus ostreatus by Box-Behnken statistical design. Carbohyd $P$. 2010;80(1):242-247.

27. Baş D, Boyacı İH. Modeling and optimization I: Usability of response surface methodology. Journal of Food Engineering. 2007;78(3):836-45.

28. Gómez-López MD, Bayo J, García-Cascales MS, Angosto JM. Decision support in disinfection technologies for treated wastewater reuse. J Cleaner Prod. 2009;17(16):1504-11.

29. Toor R, Mohseni M. UV-H2O2 based AOP and its integration with biological activated carbon treatment for DBP reduction in drinking water. Chemosphere. 2007;66(11):2087-95.

30. Lee H, Zhou B, Liang W, Feng H, Martin SE. Inactivation of Escherichia coli cells with sonication, manosonication, thermosonication, and manothermosonication: Microbial responses and kinetics modeling.J Food Eng. 2009;93(3):354-64.

31. Tsukamoto I, Constantinoiu E, Furuta M, Nishimura R, Maeda $\mathrm{Y}$. Inactivation effect of sonication and chlorination on Saccharomyces cerevisiae. Calorimetric analysis. Ultrason Sonochem. 2004;11(3-4):167-72.

32. Ince NH, Tezcanli G, Belen RK, Apikyan İG. Ultrasound as a catalyzer of aqueous reaction systems: the state of the art and environmental applications. Appl Catal B: Env. 2001;29(3):167-76.

33. Doosti MR, Kargar R, Sayadi MH. Water treatment using ultrasonic assistance: A review. P Int Acad Ecology and Env Sci. 2012;2(2):96110 .

34. Gogate PR, Pandit AB. A review of imperative technologies for wastewater treatment I: oxidation technologies at ambient conditions. Advan Env Res. 2004;8(3-4):501-51

35. Goncharuk VV, Malyarenko VV, Yaremenko VA. Use of ultrasound in water treatment.J Water Chem Technol. 2008;30(3):137-50.

36. Mahvi AH. Application of ultrasonic technology for water and wastewater treatment. Iran J Public Health. 2009;38(2).

37. Mason TJ, Joyce E, Phull SS, Lorimer JP. Potential uses of ultrasound in the biological decontamination of water. Ultrason Sonochem. 2003;10(6):319-23.

38. Broekman S, Pohlmann O, Beardwood ES, de Meulenaer EC. Ultrasonic treatment for microbiological control of water systems. Ultrason Sonochem. 2010;17(6):1041-8.

39. Butz P, Tauscher B. Emerging technologies: chemical aspects Food Res Int. 2002;35(2-3):279-84

40. Umar M, Aziz HA, Yusoff MS. Assessing the chlorine disinfection of landfill leachate and optimization by response surface methodology (RSM). Desalination. 2011;274(1-3):278-83.

41. Munoz A, Palgan I, Noci F, Morgan DJ, Cronin DA, Whyte P, et al. Combinations of High Intensity Light Pulses and Thermosonication for the inactivation of Escherichia coli in orange juice. Food Microbiol. 2011;28(6):1200-4.

42. Sostaric JZ, Weavers LK. Advancement of high power ultrasound technology for the destruction of surface active waterborne contaminants. Ultrason Sonochem. 2010;17(6):1021-6.

43. Marques LLM, Buzato JB, Celligoi MAPC. Effect of raffinose and ultrasound pulses on invertase release by free and immobilized Saccharomyces cerevisiae in loofa (Luffa cylindrica) sponge. Braz Arch Biol Technol. 2006;49(6):873-80.

44. Lanchun S, Bochu W, Liancai Z, Jie L, Yanhong Y, Chuanren D. The influence of low-intensity ultrasonic on some physiological characteristics of Saccharomyces cerevisiae. Colloids Surfaces B: Biointerfaces. 2003;30(1-2):61-6.

45. Jean D, Chang B, Liao G, Tsou G, Lee D. Reduction of microbial density level in sewage sludge through $\mathrm{pH}$ adjustment and ultrasonic treatment. Water Sci Technol. 2000;42(9):97-102.

46. Gordon AG. Beneficial effects of ultrasound on plants-a review. Ultrasonics. 1971;9(2):81-4

47. Kuldiloke J, Eshtiaghi MN. Application of non-thermal processing for preservation of orange juice. KMITL Sci Technol J. 2008;8(2):64-74.

48. Guerrero S, López-Malo A, Alzamora SM. Effect of ultrasound on the survival of Saccharomyces cerevisiae: influence of temperature, $\mathrm{pH}$ and amplitude. Innovative Food Sci Emerg Technol. 2001;2(1):31-9. 


\section{Gholami M et al.}

49. Raso G, D'Amore M, Formisani B, Lignola PG. The influence of temperature on the properties of the particulate phase at incipient fluidization. Powder Technol. 1992;72(1):71-76.

50. Foladori P, Laura B, Gianni A, Giuliano Z. Effects of sonication on bacteria viability in wastewater treatment plants evaluated by flow cytometry--fecal indicators, wastewater and activated sludge. Water Res. 2007;41(1):235-43.

51. Dadjour MF, Ogino C, Matsumura S, Shimizu N. Kinetics of dis- infection of Escherichia coli by catalytic ultrasonic irradiation with TiO2. Biochem Eng J. 2005;25(3):243-8.

52. Bigelow TA, Northagen T, Hill TM, Sailer FC. The destruction of Escherichia coli biofilms using high-intensity focused ultrasound. Ultrasound Med Biol. 2009;35(6):1026-31.

53. Arrojo S, Benito Y, Tarifa AM. A parametrical study of disinfection with hydrodynamic cavitation. Ultrason Sonochem. 2008;15(5):903-8. 